\section{RMD Open}

Rheumatic \&

Musculoskeletal Diseases

\title{
Course of patients with juvenile spondyloarthritis during 4 years of observation, juvenile part of GESPIC
}

Anja Weiß, ${ }^{1}$ Kirsten Minden, ${ }^{1,2}$ Joachim Listing, ${ }^{1}$ Ivan Foeldvari, ${ }^{3}$ Joachim Sieper, ${ }^{2}$ Martin Rudwaleit ${ }^{4,5,6}$

To cite: Weiß A, Minden K, Listing J, et al. Course of patients with juvenile spondyloarthritis during 4 years of observation, juvenile part of GESPIC. RMD Open 2017;3:e000366. doi:10.1136/rmdopen-2016000366

- Prepublication history for this paper is available online. To view these files please visit the journal online (http://dx.doi.org/10.1136/ rmdopen-2016-000366)

Received 22 September 2016 Revised 3 February 2017 Accepted 7 February 2017

CrossMark

\footnotetext{
${ }^{1}$ German Rheumatism Research Center, Berlin, Germany

${ }^{2}$ Charité University Medicine Berlin, Berlin, Germany ${ }^{3}$ Hamburg Center for Pediatric Rheumatology, Hamburg, Germany

${ }^{4}$ Klinikum Bielefeld, Bielefeld, Germany

${ }^{5}$ Charite University, Medicine, Berlin, Germany

${ }^{6}$ Ghent University, Ghent, Belgium
}

Correspondence to

Anja Weiß;

weiss@drfz.de

\section{ABSTRACT}

Objective: To describe the course and the 4-year outcome of juvenile spondyloarthritis (jSpA).

Methods: Patients with a diagnosis of jSpA and an age at onset $\leq 16$ years were included in the German Spondyloarthritis Inception cohort (GESPIC) and followed up prospectively for 4 years.

Results: 118 patients (73\% men, 66\% HLA-B27 positive, mean age 13.5 years, mean symptom duration 2.2 years) were enrolled in 2 study centres: $52 \%$ of patients with jSpA were captured by the enthesitisrelated arthritis subgroup of the International League of Associations for Rheumatology classification criteria. At inclusion, the majority of patients had active peripheral arthritis $(75.4 \%)$, followed by inflammatory back pain (IBP) (19.5\%) and enthesitis (16.1\%). There was a significant improvement in clinical manifestations and in patient-reported outcomes over time. During the 4 -year follow-up, $85 \%$ of the patients had at least 1 period of remission on drug $\geq 6$ months, and $46 \%$ of the patients achieved remission $\geq 12$ months without medication, of whom $68 \%$ kept this status and $32 \%$ worsened. At the end of 4 years of observation, $23 \%$ of the patients were in remission without medication, but $57 \%$ still suffered from active disease. Patients with peripheral arthritis had a likelihood of $29 \%$ for having peripheral arthritis after 4 years, whereas the likelihood of IBP persistence was $53 \%$ for those with IBP at enrolment.

Conclusions: Although 1 quarter of patients with jSpA achieved remission off medication after 4 years, the likelihood of having recurrent or persistent disease into adulthood is substantial, particularly for jSpA with IBP.

Trial registration number: NCT 01277419 .

\section{INTRODUCTION}

Juvenile spondyloarthritis ( $\mathrm{jSpA}$ ) is a group of chronic inflammatory disease with symptom onset at 16 years of age or younger. In contrast to adult-onset spondyloarthritis (SpA), dominant clinical signs in jSpA are enthesitis and peripheral arthritis rather than

\section{Key messages}

- Our findings extend the knowledge on the disease course and outcome of juvenile spondyloarthritis under treatment with non-steroidal anti-inflammatory drugs (NSAIDs) and/or disease-modifying antirheumatic drugs (DMARDs) within a specialised care.

- In patients already treated at study entry, we observed an additional improvement over time for peripheral arthritis, uveitis, the Bath Ankylosing Spondylitis Disease Activity Index and physician's global assessment of disease activity but not for pain, inflammatory back pain and function.

- The likelihood of reaching at least one episode of remission on medication was $85 \%$ and of reaching the status of remission off medication at least once was $46 \%$.

- Our results provide guidance to physicians in counselling patients and their parents on the expected outcome of certain disease manifestations 4 years after treatment with NSAIDS or conventional DMARDs.

inflammatory back pain (IBP). ${ }^{1}$ Frequently, knee(s), ankle(s) and hips are affected. Boys are more frequently affected than girls, and HLA-B27 positivity, a positive family history and uveitis are also characteristics of jSpA. A minority of these patients develop ankylosing spondylitis (AS) prior to the age of 16, which is defined as juvenile-onset AS. Juvenile-onset AS differs in the first symptoms, the clinical picture, the frequency of manifestations at onset and severity in course of disease from adult-onset $\mathrm{AS}{ }^{1-4}$

The International League of Associations for Rheumatology (ILAR) developed classification criteria for juvenile idiopathic arthritis (JIA). ${ }^{5}$ Within the JIA classification criteria, jSpA was not considered as one disease entity. ${ }^{1}$ Most patients with jSpA fulfil criteria of enthesitis-related arthritis (ERA). 
However, within the ILAR system, patients with psoriasis or a positive family history for psoriasis are excluded from the ERA group but are considered to belong to the jSpA spectrum. ${ }^{1}{ }^{4}$ For this reason and to take the concept of $\mathrm{SpA}$ as a group of inter-related disorders with shared clinical features into account, the European Spondyloarthropathy Study Group (ESSG) criteria $^{6}$ for adult SpA were applied in this study. The ESSG criteria have previously been shown to perform well also in juveniles with $\mathrm{SpA}^{78}$

The knowledge on the course and the outcome of jSpA from published studies is limited. ${ }^{9-22}$ Available studies were mainly based on JIA cohorts, and therefore, the subgroup of ERA or jSpA constituted often small subgroups in these JIA cohorts. An unfavourable outcome was reported for ERA or jSpA in most of these studies. ${ }^{10} 1113151722$ According to Minden et al, ${ }^{10}$ only $16 \%$ of patients with jSpA achieved remission during 5 years of follow-up and more than half of the patients had active disease after $\sim 15$ years of follow-up. ${ }^{11} 17$ Early diagnosis and treatment is important because jSpA can be a progressive disease. ${ }^{23}$

We used data from the juvenile arm of the German Spondyloarthritis Inception Cohort (GESPIC) ${ }^{24}$ (clinical trials.gov NCT 01277419) to describe the course and the 4-year outcome in a larger group of patients with jSpA. GESPIC was initiated in the prebiological era to investigate prospectively the long-term outcome of early stages of AS and SpA. Juveniles and adults were included in two different subcohorts. Here, we first report on the juvenile part and describe

1. to what degree clinical signs of disease and patientreported outcomes improved or worsened,

2. the proportion of patients who still have an active disease after 4 years of observation, and

3. the probability of an arthritis, enthesitis or IBP-free outcome in patients who suffered from these symptoms.

\section{PATIENTS AND METHODS}

\section{Study design}

GESPIC is a prospective longitudinal cohort of patients with early SpA conducted in various centres across Germany. For the juvenile arm of GESPIC, patients had to have a diagnosis of juvenile SpA according to the rheumatologist's judgement and, similar to inclusion criteria among adult patients with SpA, patients with jSpA should additionally fulfil either the modified New York criteria for AS or the ESSG criteria for SpA, the latter with minor modifications: HLA-B27, dactylitis and acute anterior uveitis were added to the list of parameters of which at least one parameter must be present. ${ }^{6}{ }^{25}$ In addition, patients had to have IBP or peripheral synovitis at study entry. Patient's age at symptoms onset had to be $\leq 16$ years and age at study start had to be $<18$ years. There were no restrictions regarding disease duration or type of treatment. Patients were enrolled consecutively in 2 out of 15 GESPIC study centres between February
2002 and December 2003. These 2 centres were specialised in paediatric rheumatology only, while the remaining 13 GESPIC centres cared for adult patients only. Clinical status was assessed at baseline and every 6 months for 4 years. Informed consent was obtained from all patients and their parents. The study was performed in accordance with the Declaration of Helsinki. Ethical approval was obtained by the Ethics Commission of the Freie Universität Berlin.

\section{Outcome assessments}

Outcome assessments are based on questionnaires for patients with juvenile SpA that were completed by physicians and patients or their parents, respectively. Peripheral arthritis was defined as a joint with swelling not due to deformity or joints with loss of motion plus pain and/or tenderness. Enthesitis was assessed clinically at the iliac crest, greater trochanter, medial condyle, lateral condyle, achilles tendon and plantar fascia; additional enthesitic sites could be documented as well. Physician's global assessment of disease activity, patient's global assessment and global pain were assessed on 0-10 numerical rating scales in which higher scores indicate higher disease activity or more severe pain, respectively. The Bath Ankylosing Spondylitis Disease Activity Index (BASDAI ${ }^{26}$ was applied to measure disease activity. In a post hoc analysis, we furthermore calculated the Disease Activity Score for AS (ASDAS) with erythrocyte sedimentation rate $(\mathrm{ESR})^{27}$ which was developed after the start of this study. Physical function was measured by the Bath Ankylosing Spondylitis Functional Index (BASFI, scale $0-10)^{26}$ and by the Childhood Health Assessment Questionnaire (CHAQ) ${ }^{28}$ ranging from 0 (no disability) to 3 (very severe disability). The Questionnaire for Measuring Health-Related Quality of Life in children and adolescents (KINDL) ${ }^{29}$ is a German self-reported instrument. It can be analysed individually in its six dimensions (physical well-being, emotional well-being, self-esteem, family, friends and everyday functioning in school), and disease as an optional subscale, or in a total score. The KINDL ranges from 0 to 100 . Higher scores indicate a better quality of life.

Remission was defined based on the Wallace criteria. ${ }^{30}$ To consider the specific characteristics of jSpA, the criteria were modified. For inactive disease, six of the following had to be fulfilled: physician's global assessment of disease activity score of 0 , no joints with peripheral arthritis, no uveitis or enthesitis, morning stiffness $<15 \mathrm{~min}$, no IBP and either ESR $\leq 20 \mathrm{~mm} /$ hour or C reactive protein (CRP) level $\leq 5 \mathrm{mg} / \mathrm{L}$. By definition, patients who did not fulfil these criteria had active disease. We distinguished two types of remission: clinical remission on medication (defined by inactive disease for at least 6 months on medication) and remission off medication (defined by inactive disease for at least 12 months and without any medication). Assessment of SpondyloArthritis international Society (ASAS) classification criteria were assessed. ${ }^{31}$ 
In patients with IBP, imaging was intended but was rarely performed and therefore excluded from further analysis.

\section{Statistical methods}

All patients enrolled were included in the analysis. Owing to a high portion of patients with undifferentiated SpA (84\%), no stratification according to specific SpA subgroups was performed.

To test whether there were changes in the clinical status over time, linear mixed models and generalised estimation equations (GEE) were used: mixed models were applied to estimate mean changes, and GEE models to estimate changes in the percentages of patients with specific clinical characteristics. For the analysis of remission, Breslow-type estimates of likelihood of achieving remission were used. The t-test and non-parametric Wilcoxon test were applied to compare HLA-B27-positive and HLA-B27-negative patients at baseline.

Patients lost to follow-up were compared with completers based on clinical data (BASDAI, pain, peripheral arthritis (yes/no), enthesitis (yes/no)) assessed at the last study visit of the dropouts and the corresponding visit of the completers. Since these comparisons did not result in significant differences (data not shown), an adjustment for a possible confounding by patients lost to follow-up was not performed. $p$ Values of $<0.05$ were considered to be statistically significant.

\section{RESULTS}

\section{SpA subgroups and classification}

In total, 118 patients with jSpA were enrolled. Ninety-nine patients $(84 \%)$ were diagnosed as having undifferentiated $\mathrm{SpA}$, nine $(8 \%)$ with reactive arthritis $(\operatorname{ReA})$, seven $(6 \%)$ with psoriatic-SpA (Pso-SpA) and three $(2.5 \%)$ with juvenile AS. All patients fulfilled the modified ESSG criteria and three patients the modified New York criteria for AS either at enrolment or before. The classification of the patients with jSpA according to the $\operatorname{ILAR}^{5}$ criteria system was as follows: 61 patients (52\%) fulfilled the criteria of ERA, $11(9 \%)$ for psoriatic arthritis, $10(9 \%)$ for rheumatoid factor (RF)-negative polyarthritis, 4 (3\%) for RF-positive polyarthritis, 7 (6\%) for oligoarthritis and $18(15 \%)$ were classified as cases of undifferentiated arthritis. There were seven (6\%) patients with missing ILAR classification. One hundred and fifteen $(97 \%)$ patients fulfilled the ASAS classification criteria.

\section{Disease demographics and characteristics prior to and at enrolment}

Seventy-three per cent of the patients were men, and $66 \%$ were HLA-B27 positive. Prior to study enrolment, nearly all of the patients ever had peripheral arthritis $(96 \%)$. The most frequently affected joints were knees $(77 \%)$, ankles $(40 \%)$, hips $(38 \%)$, toes $(27 \%)$ and fingers $(25 \%)$. Signs of symmetrical arthritis were observed in approximately half of the patients who had arthritis of the feet or fingers. Forty-four per cent of the patients ever suffered from enthesitis and 6-13\% from psoriasis, uveitis, tarsitis or dactylitis (table 1). At enrolment, $75 \%$ of the patients suffered from peripheral arthritis, $16 \%$ from enthesitis and $20 \%$ from IBP (table 1 ).

\section{Disease manifestations in relation to HLA-B27 status}

HLA-B27-positive and HLA-B27-negative patients differed in physician's global assessments of disease activity (mean (SD): 2.2 (1.5) vs 1.5 (1.2); $\mathrm{p}=0.007$ ), age, family history, CRP and ESR (table 2). In other physician and patient-reported outcomes, no significant differences were observed between HLA-B27-positive and HLA-B27-negative patients (data not shown).

\section{Treatment and disease activity during follow-up}

At enrolment, $96 \%$ of the patients with jSpA received medical therapy. There was a strong decrease in the portion of patients treated with non-steroidal antiinflammatory drugs (NSAIDs) and a smaller decrease in disease-modifying antirheumatic drug (DMARD) treatment over time (table 3). This resulted in a significant and clear increase in the percentage of patients who did not receive any treatment with NSAIDs, DMARDs or glucocorticoids.

Although disease activity at enrolment was an assessment under treatment in the vast majority of the patients with jSpA (96\%), further significant improvements in arthritis, enthesitis, mean number of joints with limited range of motion, BASDAI, BASFI, CHAQ, patient's and physician's global assessment of disease activity were observed during 4 years of observation (table 4).

After 4 years, active disease was present in $57 \%$ of the patients: $18 \%$ had peripheral arthritis, $14 \%$ had IBP, $3 \%$ suffered from enthesitis and $9 \%$ had an ESR > $20 \mathrm{~mm} /$ hour.

Other SpA manifestations occurred in one-fifth of the patients during the 4 years of follow-up: 13\% reported dactylitis, and $6 \%$ reported psoriasis at study enrolment, which resolved completely after 4 years of follow-up. A new onset of dactylitis and tarsitis was observed in five and four patients, respectively. Psoriasis and uveitis were reported newly by three patients each. Urethritis and chronic inflammatory bowel disease were observed in one patient, and diarrhoea (more than once a month) in four patients during 4 years of follow-up.

Three patients had a diagnosis of juvenile AS at enrolment and three further patients developed juvenile AS.

\section{Quality of life}

Quality of life was assessed by the total KINDL score and its subscales which range from 0 to 100 . Patients in this cohort started with a KINDL mean total score of 76 $(\mathrm{SD}=12.3)$. Considering the KINDL subscales at study enrolment, we found that 'family' had the highest value (mean (SD): 84 (14.3)) and 'disease' the lowest value 
Table 1 Clinical characteristics ever and at study enrolment

\begin{tabular}{|c|c|c|}
\hline & \multicolumn{2}{|l|}{ Juvenile SpA $(n=118)$} \\
\hline & $\begin{array}{l}\text { Clinical manifestations ever } \\
\text { before study enrolment }{ }^{\star}\end{array}$ & $\begin{array}{l}\text { Clinical manifestations/findings } \\
\text { at study enrolment }\end{array}$ \\
\hline Peripheral arthritis, $\mathrm{n}(\%)$ & $113(95.8)$ & $89(75.4)$ \\
\hline Arthritis joint count $(0-64)$, mean (SD) & $5.1(5.7)$ & $2.0(2.3)$ \\
\hline \multicolumn{3}{|l|}{ Arthritis joint count $(0-64), \mathrm{n}(\%)$} \\
\hline 0 & $5(4.2)$ & 27 (23.3) \\
\hline 1 & $15(12.7)$ & 34 (29.3) \\
\hline $2-4$ & $54(45.8)$ & $45(38.8)$ \\
\hline 5 or more & $44(37.3)$ & $10(8.6)$ \\
\hline Enthesitis, n (\%) & $52(44.1)$ & $19(16.1)$ \\
\hline Enthesitis count (0-12), mean (SD) & $0.9(1.4)$ & $0.3(0.8)$ \\
\hline \multicolumn{3}{|l|}{ Enthesitis count $(0-12), \mathrm{n}(\%)$} \\
\hline 0 & $66(56.9)$ & $95(84.1)$ \\
\hline 1 & $22(19)$ & $11(9.7)$ \\
\hline $2-4$ & $25(21.6)$ & 6 (5.3) \\
\hline 5 or more & $3(2.6)$ & $1(0.9)$ \\
\hline Inflammatory back pain, n (\%) & 38 (32.2) & $23(19.5)$ \\
\hline Dactylitis, n (\%) & $15(12.7)$ & $3(2.5)$ \\
\hline Tarsitis, n (\%) & $11(9.3)$ & $10(8.5)$ \\
\hline Psoriasis, $\mathrm{n}(\%)$ & $7(5.9)$ & $7(5.9)$ \\
\hline Uveitis, n (\%) & $8(6.8)$ & $3(2.5)$ \\
\hline $\mathrm{CRP}(\mathrm{mg} / \mathrm{L})$, mean $(\mathrm{SD})$ & - & $9(14.9)$ \\
\hline $\mathrm{CRP} \geq 5 \mathrm{mg} / \mathrm{L}, \mathrm{n}(\%)$ & - & 48 (50.5) \\
\hline ESR (mm/hour), mean (SD) & _- & $16.2(16.4)$ \\
\hline ESR $>20 \mathrm{~mm} /$ hour, $\mathrm{n}(\%)$ & - & 27 (22.9) \\
\hline
\end{tabular}

Table 2 Patient characteristics at study enrolment by HLA-B27 status

\begin{tabular}{llllc}
\hline & $\begin{array}{l}\text { HLA-B27 } \\
\text { positive, } \mathbf{n = 7 8}\end{array}$ & $\begin{array}{l}\text { HLA-B27 } \\
\text { negative, } \mathbf{n = 4 0}\end{array}$ & $\begin{array}{c}\text { p Value } \\
\text { Age at study start, mean (SD) }\end{array}$ & $\begin{array}{l}\text { All patients, } \\
\mathbf{n}=\mathbf{1 1 8}\end{array}$ \\
\hline Male, $\mathrm{n}(\%)$ & $13.9(2.5)$ & $12.6(2.8)$ & 0.008 & $13.5(2.7)$ \\
Symptom duration (years), mean (SD) & $60(77)$ & $26(65)$ & 0.168 & $86(73)$ \\
Duration since diagnosis (years), mean (SD) & $2.3(2.1)$ & $2.1(1.5)$ & 0.551 & $2.2(1.9)$ \\
Positive family history for SpA, $\mathrm{n}(\%)$ & $1.6(1.8)$ & $1.4(1.5)$ & 0.788 & $1.5(1.7)$ \\
CRP (mg/L), mean (SD) & $29(37)$ & $31(78)$ & 0.0001 & $60(51)$ \\
CRP $\geq 5$ mg/L, $n$ (\%) & $9.8(15.9)$ & $7.7(13.1)$ & 0.001 & $9(14.9)$ \\
ESR (mm/hour), mean (SD) & $40(51)$ & $8(20)$ & 0.0001 & $48(50.5)$ \\
ESR >20 mm/hour, $\mathrm{n}(\%)$ & $19(18.3)$ & $10.9(9.9)$ & 0.002 & $16.2(16.4)$ \\
\hline
\end{tabular}

CRP, C reactive protein; $\mathrm{ESR}$, erythrocyte sedimentation rate; $\mathrm{SpA}$, spondyloarthritis.

(mean (SD): 57 (12.3)). Significant improvement from study start until year 4 was observed for the subscales 'physical wellbeing' (mean (SD) from 80 (13.7) to 85 (12.3); $\mathrm{p}=0.036$ ) and 'friends' (from 75 (17.6) to 84 (11.7); $\mathrm{p}=0.013)$.

\section{Achievement of remission}

The cumulative portion of patients achieving remission on and off medication is shown in figure $1 \mathrm{~A}$. By the end of 4 years, $85 \%$ of the patients had at least one period of remission on medication. In $49 \%$ of the remission periods on medication, treatment was terminated and remission off medication was maintained 6 months later (figure 1B), whereas $13 \%$ remained in the status of remission on medication, and $38 \%$ flared. The likelihood of achieving a status of remission off medication at least once during observation was $46 \%$ (figure 1A). The probability of remaining in this status was $68 \%$, and that of a flare $32 \%$ (figure $1 \mathrm{~B}$ ).

\section{Outcome at 4 years of follow-up}

Using GEE models, we estimated the outcome (remission or active disease) after 4 years for all patients enrolled $(n=118)$ and the outcome of certain disease manifestations in patients with or without such manifestations at baseline (table 5). The likelihood of having 
Table 3 Treatment at baseline reflecting the past 6 months and at follow-up

\begin{tabular}{|c|c|c|c|c|c|c|}
\hline Therapy & $\begin{array}{l}\text { At study enrolment } \\
n=118\end{array}$ & $\begin{array}{l}\text { Month } 6 \\
n=117\end{array}$ & $\begin{array}{l}\text { Year } 1 \\
n=114\end{array}$ & $\begin{array}{l}\text { Year } 2 \\
n=104\end{array}$ & $\begin{array}{l}\text { Year } 3 \\
n=93\end{array}$ & $\begin{array}{l}\text { Year } 4 \\
n=68\end{array}$ \\
\hline No therapy, $n(\%)$ & $5(4.2)$ & $31(27.4)$ & 37 (35.9) & $47(53.4)$ & $39(56.5)$ & $41(69.5)$ \\
\hline NSAID, $\mathrm{n}(\%)$ & $101(85.6)$ & $78(66.7)$ & $60(52.6)$ & $38(35.5)$ & $25(26.9)$ & $16(23.5)$ \\
\hline csDMARD, n (\%) & 48 (40.7) & $51(43.6)$ & $45(39.5)$ & $27(25.2)$ & $17(18.3)$ & $12(17.6)$ \\
\hline Methotrexate, n (\%) & $26(22)$ & $25(21.4)$ & $22(19.3)$ & $11(10.3)$ & $11(11.8)$ & $8(11.8)$ \\
\hline Sulfasalazine, n (\%) & $17(14.4)$ & $22(18.8)$ & $18(15.8)$ & $12(11.2)$ & $5(5.4)$ & $4(5.9)$ \\
\hline bDMARD (TNFi), n (\%) & $5(4.2)$ & $5(4.3)$ & $4(3.5)$ & $6(5.6)$ & $5(5.4)$ & $4(5.9)$ \\
\hline Combination NSAID and DMARDs, n (\%) & $36(30.5)$ & $31(26.5)$ & $29(25.4)$ & $18(16.8)$ & $8(8.6)$ & $5(7.4)$ \\
\hline Glucocorticoids >0.2 mg/kg, n (\%) & $10(8.5)$ & $1(0.9)$ & $1(0.9)$ & $1(0.9)$ & $1(1.1)$ & $0(0)$ \\
\hline Glucocorticoids $\leq 0.2$ mg/kg, n (\%) & $8(6.8)$ & $6(5.1)$ & $2(1.8)$ & $2(1.9)$ & $1(1.1)$ & $1(1.5)$ \\
\hline Glucocorticoids, intra-articular, n (\%) & $18(15.3)$ & $8(6.8)$ & $4(3.5)$ & $3(2.8)$ & $2(2.2)$ & $0(0)$ \\
\hline
\end{tabular}

bDMARD, biological disease-modifying antirheumatic drug; csDMARD, conventional synthetic disease-modifying antirheumatic drug; NSAID, non-steroidal anti-inflammatory drug; TNFi, tumour necrosis factor inhibitor.

Table 4 Clinical manifestations and assessments from study enrolment until year 4

\begin{tabular}{|c|c|c|c|c|c|c|c|}
\hline Clinical parameter* & $\begin{array}{l}\text { At study } \\
\text { enrolment } \\
n=118\end{array}$ & $\begin{array}{l}\text { Month } 6 \\
n=117\end{array}$ & $\begin{array}{l}\text { Year } 1 \\
n=114\end{array}$ & $\begin{array}{l}\text { Year } 2 \\
n=104\end{array}$ & $\begin{array}{l}\text { Year } 3 \\
n=93\end{array}$ & $\begin{array}{l}\text { Year } 4 \\
n=68\end{array}$ & p Value \\
\hline \multicolumn{8}{|l|}{ Current status } \\
\hline Arthritis, n (\%) & $89(75.4)$ & $60(51.3)$ & $44(38.6)$ & $19(17.8)$ & $13(14)$ & $12(17.6)$ & 0.0001 \\
\hline Arthritis joint count (0-64), mean (SD) & $2.0(2.3)$ & $1.3(2.1)$ & $1.0(1.8)$ & $0.4(1.1)$ & $0.3(0.7)$ & $0.5(1.1)$ & 0.0001 \\
\hline $\begin{array}{l}\text { Joints with limited range of motion, } \\
\mathrm{n}(\%)\end{array}$ & $70(59.3)$ & $63(53.8)$ & $57(50)$ & $33(30.8)$ & $23(24.7)$ & $28(41.2)$ & 0.615 \\
\hline $\begin{array}{l}\text { Joints with limited range of motion, } \\
\text { mean (SD) }\end{array}$ & $1.5(1.4)$ & $1.4(1.6)$ & $1.3(1.4)$ & $0.9(1.4)$ & $0.9(1.6)$ & $1.1(1.2)$ & 0.015 \\
\hline Enthesitis, n (\%) & $19(16.1)$ & $11(9.4)$ & $12(10.5)$ & $6(5.6)$ & $2(2.2)$ & $2(2.9)$ & 0.079 \\
\hline Enthesitis count (0-12), mean (SD) & $0.3(0.8)$ & $0.1(0.5)$ & $0.2(0.6)$ & $0.1(0.5)$ & $0.02(0.1)$ & $0.1(0.6)$ & 0.513 \\
\hline Inflammatory back pain, n (\%) & $23(19.7)$ & $16(14.5)$ & $11(10.9)$ & $14(16.9)$ & $8(11.9)$ & 7 (13.7) & 0.58 \\
\hline $\begin{array}{l}\text { Patient's global assessment } \\
\text { (0-10 NRS), mean (SD) }\end{array}$ & n.d. & $2.9(2.6)$ & $2.1(2.2)$ & $2.2(2.7)$ & $1.8(2.3)$ & $2.3(2.9)$ & 0.006 \\
\hline Pain (0-10 NRS), mean (SD) & $2.5(2.3)$ & $1.9(2.1)$ & $1.5(1.8)$ & $1.6(2.3)$ & $1.4(2.1)$ & $1.3(1.9)$ & 0.244 \\
\hline ASDAS (0-10), mean (SD) & n.d. & $1.6(0.7)$ & $1.4(0.7)$ & $1.4(0.8)$ & $1.4(0.8)$ & $1.3(0.6)$ & 0.092 \\
\hline BASDAI (0-10), mean (SD) & $2.0(1.7)$ & $1.6(1.5)$ & $1.3(1.3)$ & $1.4(1.4)$ & $1.1(1.1)$ & $1.0(1.1)$ & 0.002 \\
\hline BASFI (0-10), mean (SD) & $0.7(1.0)$ & $0.6(1.0)$ & $0.4(0.7)$ & $0.4(0.9)$ & $0.3(0.6)$ & $0.3(0.5)$ & 0.002 \\
\hline CHAQ (0-3), mean (SD) & $0.2(0.3)$ & $0.2(0.4)$ & $0.1(0.2)$ & $0.1(0.3)$ & $0.1(0.2)$ & $0.1(0.2)$ & 0.0001 \\
\hline KINDL (0-100), mean (SD) & 76 (12.3) & 77 (12.3) & $79(11.8)$ & $80(11.8)$ & $81(13.0)$ & $82(11.9)$ & 0.165 \\
\hline \multicolumn{8}{|l|}{ Current or within the past 6 months } \\
\hline Arthritis, n (\%) & $113(95.8)$ & $83(70.9)$ & $60(52.6)$ & $30(28)$ & $17(18.3)$ & $15(22.1)$ & 0.0001 \\
\hline Enthesitis, n (\%) & $52(44.1)$ & $28(23.9)$ & $20(17.5)$ & $10(9.3)$ & $4(4.3)$ & $2(2.9)$ & 0.0001 \\
\hline Inflammatory back pain, n (\%) & $38(32.2)$ & $20(18.2)$ & $14(13.9)$ & $19(22.9)$ & $11(16.4)$ & 9 (16.7) & 0.495 \\
\hline $\begin{array}{l}\text { Physician's global assessment } \\
\text { (0-10 NRS), mean (SD) }\end{array}$ & $2.0(1.5)$ & $1.6(1.3)$ & $1.4(1.3)$ & $1.3(1.3)$ & $0.9(1.0)$ & $1.0(1.1)$ & 0.0003 \\
\hline Uveitis, n (\%) & $8(6.8)$ & $2(1.7)$ & $3(2.6)$ & $1(0.9)$ & $1(1.1)$ & $4(5.9)$ & 0.07 \\
\hline Remission on medication, $\mathrm{n}(\%)$ & $0(0)$ & $6(5.6)$ & $10(10.4)$ & $21(25.6)$ & $23(34.8)$ & $23(43.4)$ & 0.0001 \\
\hline Remission off medication, $\mathrm{n}(\%)$ & - & $0(0)$ & $2(2.1)$ & $3(3.7)$ & $7(10.6)$ & $12(22.6)$ & 0.0004 \\
\hline
\end{tabular}

active disease after 4 years has also been estimated according to HLA-B27 status, gender and family history (table 5).

Accordingly, we calculated a $71 \%$ chance of being arthritis-free after 4 years for patients with peripheral arthritis at baseline. The percentage of an enthesitis-free outcome for patients with enthesitis at study entry was even higher $(92 \%)$. Inversely, for patients with IBP at study enrolment, there was still a $53 \%$ risk that symptoms of IBP sustained. This approach confirms that almost 
Figure 1 (A) Cumulative likelihood of achieving remission on and off medication. (B)

Transition probabilities: left: transition probability of a status in remission on medication; right: transition probability of a status in remission off medication.

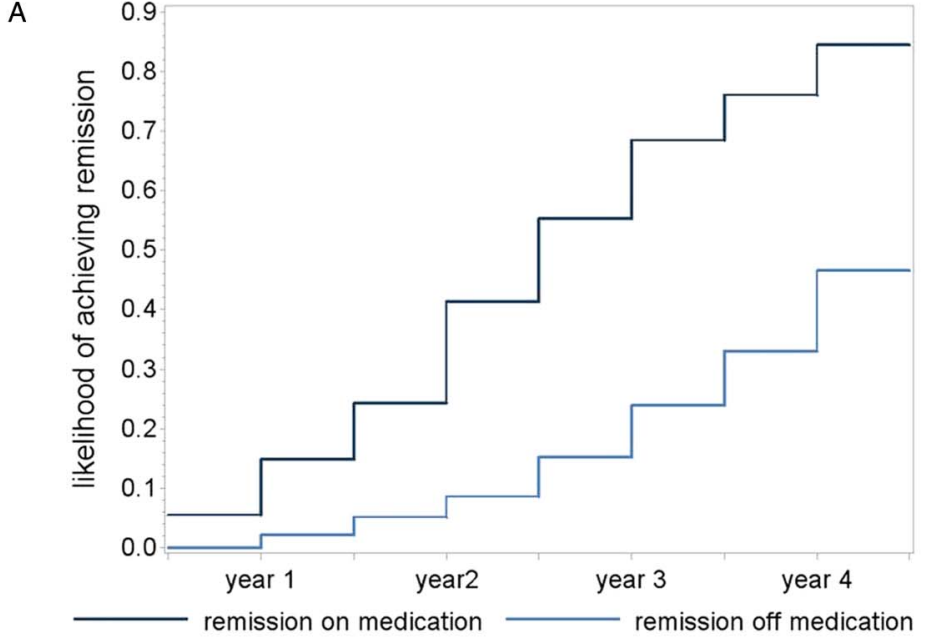

B
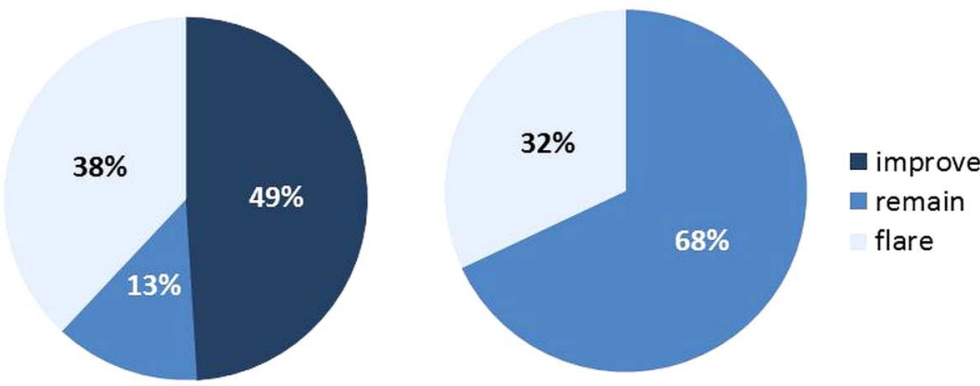

remission on medication

Table 5 Likelihood of having peripheral arthritis, enthesitis, inflammatory back pain or active disease at year 4 depending on status at study entry

\section{Status at study entry}

Peripheral arthritis present

Peripheral arthritis present $(n=82)$

No peripheral arthritis $(\mathrm{n}=26)$

Enthesitis present

Enthesitis present $(n=18)$

No enthesitis $(n=88)$

IBP present

IBP present $(n=23)$

No IBP $(\mathrm{n}=94)$

Active disease present

All patients

HLA-B27 positive $(n=73)$

HLA-B27 negative $(n=37)$

Male $(n=79)$

Female $(n=31)$

Positive SpA family history $(n=57)$

No SpA family history $(n=41)$

Likelihood of a certain disease status is expressed in per cent; $95 \%$ confidence limits are shown in parentheses.

half of the patients (54\%) still had an active disease 4 years after enrolment. The likelihood of having active disease was higher in HLA-B27-positive patients, women and patients without a family history of SpA.

\section{DISCUSSION}

Our prospective, 4-year observational study of patients with jSpA clearly extends the knowledge currently available from small groups of patients with $\mathrm{jSpA}$ as a subgroup of JIA cohorts ${ }^{101632}$ and one larger study, which, however, had to deal with a high loss to follow-up. ${ }^{18}$ In our cohort, $85 \%$ of the patients with jSpA reached at least one episode of remission on medication during 4 years of follow-up in specialised paediatric rheumatology care. The likelihood of reaching a status of remission off medication at least once was $46 \%$. However, these remission episodes were not stable. After 4 years of follow-up, $23 \%$ of the patients were in remission without medication; yet nearly one out of five patients had peripheral arthritis and a similar portion had IBP. In total, half of the patients had an active disease.

Guzman et $a l^{18}$ found cumulative probabilities of attaining inactive disease in patients with ERA within 4 years of $93 \%$ which is even higher than our remission on medication rate of $85 \%$, but our modification of the Wallace criteria was stricter, too.

Our findings agree with those of others who also found high rates of active disease in the long-term follow-up of patients with ERA or jSpA. ${ }^{10} 1317$ Remission rates in patients with ERA were found to be significantly lower than in patients with oligoarthritis, ${ }^{10} 1517$ and also lower than in patients with polyarticular JIA. ${ }^{15} 1718$ The low remission rates correspond to poorer physical function, more bodily pain and reduced spinal flexion in the 
long term in patients with ERA compared with those with persistent oligoarticular or polyarticular JIA. ${ }^{17}$ These remission rates may have changed recently since tumour necrosis factor inhibitors are now increasingly used in the treatment of jSpA. Treatment with these biologics played a negligible role in our inception cohort as well as in previous other studies. In one study, male sex and a positive family history were found to be associated with a poorer outcome. ${ }^{15}$ Our data did not confirm these findings. In JIA in general, HLA-B27 positivity was found to be associated with a poorer outcome. ${ }^{10}{ }^{15} \mathrm{~A}$ similar, yet statistically non-significant, trend was seen even within the patients with jSpA in our cohort as well as in another ERA cohort. ${ }^{15}$

Flato $e t a l^{33}$ found that a long disease duration before first admission is a predictor of a progressive disease, a worse functional outcome and disease persistence into adulthood. ${ }^{17}{ }^{33}$ We were not able to evaluate this aspect, since we did not collect the respective information and nearly all of our patients were already treated at enrolment.

We asked whether the clinical status achieved in specialised care could further improve during the following 34 years, and if treatment with NSAIDs and/or DMARDs is being tapered whenever appropriate. We observed an additional improvement over time for peripheral arthritis, uveitis, BASDAI and physician's global assessment of disease activity but not for pain, IBP and BASFI. Selvaag et $a \hat{l}^{22}$ found similar results of a significant improvement in disease activity and health status but not in pain for patients with juvenile rheumatoid arthritis and jSpA during 3 years of observation. Oen et $a l^{14}$ analysed patients with JIA within 6 months after diagnosis who were treated with a limited number of therapies, and found improvements until 6 months follow-up in peripheral arthritis, physician global assessment, patient's global assessment and CHAQ in all analysed subtypes.

Our results may provide some guidance to physicians in counselling patients and their parents on the expected outcome of certain disease manifestations 4 years after treatment with NSAIDs or conventional DMARDs. We found rather high chances for patients suffering from enthesitis or arthritis at baseline to achieve an enthesitis-free or arthritis-free status at follow-up. In contrast, there was a 53\% risk that symptoms of IBP were still present 4 years later.

Klotsche et $a l^{34}$ found that an increase in health-related quality of life on therapy with etanercept is correlated to parameters of disease activity such as pain, painful and swollen joints and ESR. To assess health-related quality of life, we used the KINDL, a German self-reported generic instrument which is accepted internationally. ${ }^{35} 36$ The KINDL mean score at baseline was comparable to healthy adolescents. ${ }^{37}$ During follow-up, the subscales 'physical wellbeing' and 'friends' further improved significantly, and only the subscale 'disease' worsened.

The strength of our study is the prospective study design and the large number of patients with jSpA $(\mathrm{n}=118)$, which is larger than those in the study by Flato et al $(\mathrm{n}=55)^{17}$ and Minden et al $(\mathrm{n}=28),{ }^{10}$ and only slightly smaller than that in the study by Guzman et al $(\mathrm{n}=144) .{ }^{18}$ The retention rate after 4 years was $58 \%$ in our study, which can be considered as a weakness, yet our retention rate was much higher than the retention rate of $12 \%$ in the Guzman et al study. We furthermore possibly underestimated the percentage of patients who developed juvenile AS at follow-up due to missing imaging data.

\section{CONCLUSION}

The results of this 4-year observation cohort in juveniles with SpA describe the disease course under conventional treatment with NSAIDs and/or DMRADs in jSpA. Major clinical manifestations such as peripheral arthritis, enthesitis or extra-articular manifestations could successfully be improved. Despite early and effective treatment, there is still a rather high risk of a (residual) active disease or disease flares during 4 years of follow-up. This risk is especially high for IBP, and much lower for peripheral arthritis and enthesitis. For these reasons, our results from the prebiological era confirm the need for new treatment options also in jSpA and the necessity for a successful transition of patients with active disease to adult rheumatology care.

Acknowledgements The authors are grateful to Mrs Beate Buss for data monitoring, and to all patients and their parents who voluntarily participated in this cohort. The authors also like to thank Dr U Ravens-Sieberer for providing the Kiddo Kindl questionnaire on quality of life.

Contributors AW performed data analysis, statistical analysis, prepared tables and figures and wrote the draft manuscript. KM took care of study patients, was involved in data interpretation and manuscript preparation. JL performed statistical analysis, data interpretation and was involved in manuscript preparation. IF took care of after study patients. JS was responsible for getting funding of the trial, designed the study and was involved in manuscript preparation. MR was responsible for getting funding of the trial, designed the study and was involved in data interpretation and manuscript preparation. All authors read and approved the final manuscript.

Funding As part of the German Competence Network in Rheumatology (Kompetenznetz Rheuma), GESPIC has been financially supported by the Bundesministerium für Bildung und Forschung (BMBF), FKZ 01G19946.

Competing interests None declared.

Patient consent Obtained.

Ethics approval Ethics Commission of the Freie Universität Berlin.

Provenance and peer review Not commissioned; externally peer reviewed.

Data sharing statement No additional data are available.

Open Access This is an Open Access article distributed in accordance with the Creative Commons Attribution Non Commercial (CC BY-NC 4.0) license, which permits others to distribute, remix, adapt, build upon this work noncommercially, and license their derivative works on different terms, provided the original work is properly cited and the use is non-commercial. See: http:// creativecommons.org/licenses/by-nc/4.0/

\section{REFERENCES}

1. Tse SM, Laxer RM. New advances in juvenile spondyloarthritis. Nat Rev Rheumatol 2012;8:269-79. 
2. Burgos-Vargas R. The assessment of the spondyloarthritis international society concept and criteria for the classification of axial spondyloarthritis and peripheral spondyloarthritis: a critical appraisal for the pediatric rheumatologist. Pediatr Rheumatol Online $J$ 2012;10:14

3. O'Shea FD, Boyle E, Riarh R, et al. Comparison of clinical and radiographic severity of juvenile-onset versus adult-onset ankylosing spondylitis. Ann Rheum Dis 2009;68:1407-12.

4. Burgos-Vargas R, Rudwaleit M, Sieper J. The place of juvenile onset spondyloarthropathies in the Durban 1997 ILAR classification criteria of juvenile idiopathic arthritis. International League of Associations for Rheumatology. J Rheumatol 2002;29:869-74.

5. Petty RE, Southwood TR, Manners P, et al. International League of Associations for Rheumatology classification of juvenile idiopathic arthritis: second revision, Edmonton, 2001. J Rheumatol 2004;31:390-2.

6. Dougados $\mathrm{M}$, van der Linden $\mathrm{S}$, Juhlin $\mathrm{R}$, et al. The European Spondylarthropathy Study Group preliminary criteria for the classification of spondylarthropathy. Arthritis Rheum 1991;34:1218-27.

7. Prieur AM, Listrat V, Dougados M, et al. [Criteria for classification of spondylarthropathies in children]. Arch Fr Pediatr 1993;50:379-85.

8. Prieur AM. Evaluation of 4 sets of criteria for spondylarthropathy in children-a multicenter European cross-sectional study. Arthritis Rheum 1992;35:S190.

9. Horneff G, Fitter S, Foeldvari I, et al. Double-blind, placebo-controlled randomized trial with adalimumab for treatment of juvenile onset ankylosing spondylitis (JoAS): significant short term improvement. Arthritis Res Ther 2012;14:R230.

10. Minden K, Kiessling U, Listing J, et al. Prognosis of patients with juvenile chronic arthritis and juvenile spondyloarthropathy. $J$ Rheumatol 2000;27:2256-63.

11. Minden $\mathrm{K}$, Niewerth $\mathrm{M}$, Listing J, et al. Long-term outcome in patients with juvenile idiopathic arthritis. Arthritis Rheum 2002:46:2392-401.

12. Adib N, Hyrich $\mathrm{K}$, Thornton $\mathrm{J}$, et al. Association between duration of symptoms and severity of disease at first presentation to paediatric rheumatology: results from the Childhood Arthritis Prospective Study. Rheumatology (Oxford) 2008;47:991-5.

13. Nordal E, Zak M, Aalto $\mathrm{K}$, et al. Ongoing disease activity and changing categories in a long-term nordic cohort study of juvenile idiopathic arthritis. Arthritis Rheum 2011;63:2809-18.

14. Oen K, Duffy CM, Tse SM, et al. Early outcomes and improvement of patients with juvenile idiopathic arthritis enrolled in a Canadian multicenter inception cohort. Arthritis Care Res (Hoboken) 2010;62:527-36.

15. Berntson L, Nordal E, Aalto K, et al. HLA-B27 predicts a more chronic disease course in an 8-year followup cohort of patients with juvenile idiopathic arthritis. J Rheumatol 2013;40:725-31.

16. Flato $B$, Aasland $A$, Vinje $O$, et al. Outcome and predictive factors in juvenile rheumatoid arthritis and juvenile spondyloarthropathy. J Rheumatol 1998;25:366-75.

17. Flato B, Hoffmann-Vold AM, Reiff A, et al. Long-term outcome and prognostic factors in enthesitis-related arthritis: a case-control study. Arthritis Rheum 2006;54:3573-82.

18. Guzman J, Oen K, Tucker LB, et al. The outcomes of juvenile idiopathic arthritis in children managed with contemporary treatments: results from the ReACCh-Out cohort. Ann Rheum Dis 2015;74:1854-60.

19. Hyrich KL, Lal SD, Foster HE, et al. Disease activity and disability in children with juvenile idiopathic arthritis one year following presentation to paediatric rheumatology. Results from the Childhood Arthritis Prospective Study. Rheumatology (Oxford) 2010;49:116-22.

20. Olivieri I, Cutro MS, D'Angelo $S$, et al. Low frequency of axial involvement in southern Italian Caucasian children with HLA-B27 positive juvenile onset undifferentiated spondyloarthritis. Clin Exp Rheumatol 2012;30:290-6.

21. Rosenberg AM, Petty RE. A syndrome of seronegative enthesopathy and arthropathy in children. Arthritis Rheum 1982;25:1041-7.

22. Weiss PF, Xiao R, Biko DM, et al. Assessment of sacroiliitis at diagnosis of juvenile spondyloarthritis by radiography, magnetic resonance imaging, and clinical examination. Arthritis Care Res (Hoboken) 2016;68:187-94.

23. Stone M, Warren RW, Bruckel J, et al. Juvenile-onset ankylosing spondylitis is associated with worse functional outcomes than adult-onset ankylosing spondylitis. Arthritis Rheum 2005;53: 445-51.

24. Rudwaleit M, Haibel $\mathrm{H}$, Baraliakos $\mathrm{X}$, et al. The early disease stage in axial spondylarthritis: results from the German Spondyloarthritis Inception Cohort. Arthritis Rheum 2009:60:717-27.

25. van der Linden S, Valkenburg HA, Cats A. Evaluation of diagnostic criteria for ankylosing spondylitis. A proposal for modification of the New York criteria. Arthritis Rheum 1984;27:361-8.

26. Calin A, Garrett S, Whitelock H, et al. A new approach to defining functional ability in ankylosing spondylitis: the development of the Bath Ankylosing Spondylitis Functional Index. J Rheumatol 1994;21:2281-5.

27. Lukas C, Landewe R, Sieper J, et al. Development of an ASAS-endorsed disease activity score (ASDAS) in patients with ankylosing spondylitis. Ann Rheum Dis 2009;68:18-24.

28. Singh G, Athreya BH, Fries JF, et al. Measurement of health status in children with juvenile rheumatoid arthritis. Arthritis Rheum 1994;37:1761-9.

29. Ravens-Sieberer U, Bullinger M. Assessing health-related quality of life in chronically ill children with the German KINDL: first psychometric and content analytical results. Qual Life Res 1998;7:399-407.

30. Wallace CA, Giannini EH, Huang B, Childhood Arthritis Rheumatology Research A, et al. American College of Rheumatology provisional criteria for defining clinical inactive disease in select categories of juvenile idiopathic arthritis. Arthritis Care Res (Hoboken) 2011;63:929-36.

31. Rudwaleit M, Landewe R, van der Heijde D, et al. The development of Assessment of SpondyloArthritis international Society classification criteria for axial spondyloarthritis (part I): classification of paper patients by expert opinion including uncertainty appraisal. Ann Rheum Dis 2009;68:770-6.

32. Selvaag AM, Lien G, Sorskaar D, et al. Early disease course and predictors of disability in juvenile rheumatoid arthritis and juvenile spondyloarthropathy: a 3 year prospective study. J Rheumatol 2005;32:1122-30.

33. Flato B, Lien G, Smerdel A, et al. Prognostic factors in juvenile rheumatoid arthritis: a case-control study revealing early predictors and outcome after 14.9 years. J Rheumatol 2003;30:386-93.

34. Klotsche J, Minden $\mathrm{K}$, Thon A, et al. Improvement in health-related quality of life for children with juvenile idiopathic arthritis after start of treatment with etanercept. Arthritis Care Res (Hoboken) 2014;66:253-62.

35. Rajmil L, Serra-Sutton V, Fernandez-Lopez JA, et al. [The Spanish version of the German health-related quality of life questionnaire for children and adolescents: the Kindl]. An Pediatr (Barc) 2004;60:514-21.

36. Helseth $\mathrm{S}$, Lund T. Assessing health-related quality of life in adolescents: some psychometric properties of the first Norwegian version of KINDL. Scand J Caring Sci 2005;19:102-9.

37. Muller-Godeffroy E, Lehmann H, Kuster RM, et al. [Quality of life and psychosocial adaptation in children and adolescents with juvenile idiopathic arthritis and reactive arthritis]. $Z$ Rheumatol 2005:64:177-87. 